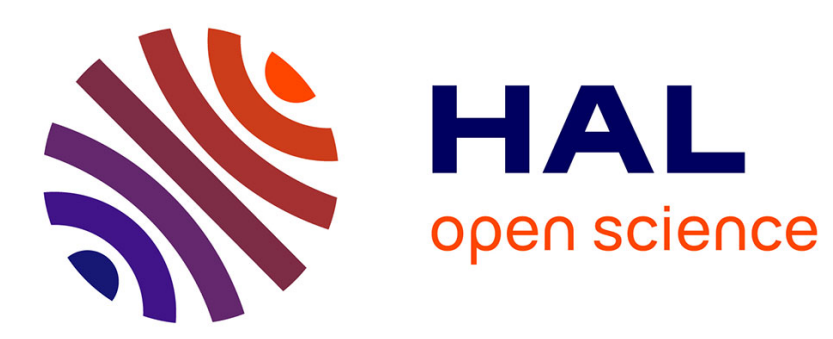

\title{
Preparation of Nickel Ferrite from thermolysis of Nickel Hexa(Formato)-Ferrate(III)Hexahydrate
}

\author{
B. Randhawa, R. Singh
}

\section{To cite this version:}

B. Randhawa, R. Singh. Preparation of Nickel Ferrite from thermolysis of Nickel Hexa(Formato)Ferrate(III)Hexahydrate. Journal de Physique IV Proceedings, 1997, 07 (C1), pp.C1-89-C1-90. 10.1051/jp4:1997125 . jpa-00254936

\section{HAL Id: jpa-00254936 https://hal.science/jpa-00254936}

Submitted on 1 Jan 1997

HAL is a multi-disciplinary open access archive for the deposit and dissemination of scientific research documents, whether they are published or not. The documents may come from teaching and research institutions in France or abroad, or from public or private research centers.
L'archive ouverte pluridisciplinaire HAL, est destinée au dépôt et à la diffusion de documents scientifiques de niveau recherche, publiés ou non, émanant des établissements d'enseignement et de recherche français ou étrangers, des laboratoires publics ou privés. 


\title{
Preparation of Nickel Ferrite from thermolysis of Nickel Hexa(Formato)-Ferrate(III)Hexahydrate
}

\author{
B.S. Randhawa and R. Singh \\ Department of Chemistry, Guru Nanak Dev University, Amritsar 143 005, India
}

\begin{abstract}
Thermal decomposition of nickel hexa(formato) ferrate(III) decahydrate i.e. $\mathrm{Ni}_{3}\left[\mathrm{Fe}(\mathrm{HCOO})_{6}\right]_{2} \cdot 10 \mathrm{H}_{2} \mathrm{O}$ has been studied upto $973 \mathrm{~K}$ in static air atmosphere employing TG,DTG,DTA,DSC,XRD,ESR, Mössbauer and infrared spectroscopic techniques. Dehydration occurs in two stages in the temperature range of 348-423 K. Immediately after the removal of the last water molecule, the anhydrous complex undergoes decomposition till $\alpha-\mathrm{Fe}_{2} \mathrm{O}_{3}$ and nickel carbonate are formed at $588 \mathrm{~K}$. In the final stage of remixing of cations, a solid state reaction between $\alpha-\mathrm{Fe}_{2} \mathrm{O}_{3}$ and nickel carbonate leads to the formation of $\mathrm{NiFe}_{2} \mathrm{O}_{4}$ at a temperature $(873 \mathrm{~K})$ much lower than for ceramic method. A high value of saturation magnetization i.e. 4440 gauss of the ferrite $\left(\mathrm{NiFe}_{2} \mathrm{O}_{4}\right)$ shows its potential to function at high frequencies.
\end{abstract}

\section{INTRODUCTION}

Ferrites find extensive application in radio, television, microwave and satellite communication, bubble devices, audio-video and digital recording and as permanent magnets [1]. The synthesis of ferrites from thermolysis of iron carboxylate precursors has two major advantages over the conventional ceramic method viz. it does not involve milling of the starting material (precursor) and ferrites are formed at much lower temperature and in shorter time. The milling which is necessary in ceramic method imparts defects and strains to the precursor which in turn affect the permanent magnetic properties of the ferrites formed [2]. We have successfully obtained ferrites from the thermolysis of alkaline earth ferrimalonates [3-5] at temperature much lower in comparison to the ceramic method. The present investigation deals with the preparation of nickel ferrite from thermolysis of nickel ferriformate.

\section{Experimental procedure}

$\mathrm{Nickel}$ hexa(formato) ferrate(III) decahydrate i.e. $\mathrm{Ni}_{3}\left[\mathrm{Fe}(\mathrm{HCOO})_{6}\right]_{2} \cdot 10 \mathrm{H}_{2} \mathrm{O}$ was prepared by mixing stoichiometric quantities of aqueous solutions of ferric chloride, nickel formate and formic acid. The reaction mixture was stirred vigorously and then concentrated on water bath until a brown colored product was formed. The brown product was filtered, washed with cold water and dried in air. The identity of the complex was established by elemental analysis. The infrared spectra of the complex ( precursor) and products were recorded on Pye-Unicam SP3-300 IR Spectro-photometer in the range $4000-200 \mathrm{~cm}^{-1}$ using KBr pellet technique. Simultaneous TG, DTG and DTA curves were recorded on Stanton Redcroft STA-780 at a heating rate of $10^{\circ} \mathrm{min}^{-1}$. DSC recording was performed on Mettler 25(Swiss) at a heating rate of $10^{\circ} \mathrm{min}^{-1}$. ESR spectra were recorded on ESR spectrometer JES-FE3XG. Magnetic measurements were made at solid state physics laboratory, Ministry of Defence, New Delhi. XRD powder pattern was recorded at BARC, Bombay. Mössbauer measurements were made at USIC, University of Roorkee, Roorkee.

\section{Results and Discussion}

The infrared spectrum of the complex, $\mathrm{Ni}_{3}\left[\mathrm{Fe}(\mathrm{HCOO})_{6}\right]_{2} \cdot 10 \mathrm{H}_{2} \mathrm{O}$ shows a broad band centered at $3300 \mathrm{~cm}^{-1}$ due to $\mathrm{v}(\mathrm{OH})$ of lattice water and a small but distinct band at $2900 \mathrm{~cm}^{-1}$ due to $v(\mathrm{C}-\mathrm{H})$.Broad bands centered at 1620 and $1350 \mathrm{~cm}^{-1}$ are attributed to $v$ asy $(\mathrm{C}=\mathrm{O})$ and $u \operatorname{sym}(\mathrm{C}=\mathrm{O})$ respectively of the coordinated formate groups. The bands at $570 \mathrm{~cm}^{-1}$ and $390 \mathrm{~cm}^{-1}$ due to $v(\mathrm{Fe}-\mathrm{O})$ suggest the presence of $\mathrm{Fe}-\mathrm{O}$ (carboxylate) bonding $[6,7]$. The six coordination number of iron is satisfied by six formate ligands which are bound through oxygen atoms of the carboxyl groups. The transition metal and water molecules seem to be responsible for linking together the complex ion [8]. A ' $\mathrm{g}$ ' value of 2.0 from esr spectrum indicates the presence of high spin iron(III) octahedral nature of the complex. Fig 1 shows the simultaneous thermal analysis (TG, DTG, DTA) curves of the complex at a heating rate of $10^{\circ}$ min ${ }^{-1}$. Presence of two plateau in TG curve suggests that dehydration occurs in two stages i.e. removal of two water molecules at $348 \mathrm{~K}$ and the remaining eight at $423 \mathrm{~K}$. There are corresponding peaks in DTG at $323 \mathrm{~K}$ and $400 \mathrm{~K}$ respectively indicating that heat changes are accompanied by weight loss. DTA shows two endotherms centered at $325 \mathrm{~K}$ and $401 \mathrm{~K}$ for dehydration. DSC (Fig. 2 ) exhibits a broad endotherm centered at $404 \mathrm{~K}$ showing a $\triangle \mathrm{H}$ value of $3.306 \mathrm{~kJ} \mathrm{~mol}^{-1}$ for dehydration. The anhydrous complex then undergoes a gradual decomposition process until a weight loss of $57.8 \%$ is obtained at $588 \mathrm{~K}$ indicating the formation of $\mathrm{Fe}_{2} \mathrm{O}_{3}$ and $\mathrm{NiCO}_{3}$ 
( calc. loss $=57.48 \%$ ). The identities of these intermediates have been confirmed by Mossbauer and infrared spectra respectively. Mössbauer spectrum of the residue obtained after heating the precursor isothermally for $30 \mathrm{~min}$ at $573 \mathrm{~K}$ exhibits a symmetrical sixline pattern with isomer shift and internal magnetic field values of $0.38 \mathrm{mms}^{-1}$ and $510 \mathrm{KOe}$ respectively indicating the formation of $-\mathrm{Fe}_{2} \mathrm{O}_{3}$ [9]. The corresponding DTG and DTA peaks exist at $568 \mathrm{~K}$ and $569 \mathrm{~K}$ (exothermic) respectively. DSC displays the corresponding exotherm at $570 \mathrm{~K}$ with a $\triangle \mathrm{H}$ value of $4.594 \mathrm{~kJ} \mathrm{~mol}^{-1}$ for the decomposition process. At higher temperature $\mathrm{NiCO}_{3}$ completely decomposes into $\mathrm{NiO}$ as shown by a weight loss of $62 \%$ at $873 \mathrm{~K}$ suggesting the presence of $\mathrm{NiFe}_{2} \mathrm{O}_{4}$ (calc. loss $=$ $61.84 \%$ ) formed as a result of solid state reaction between $\mathrm{Fe}_{2} \mathrm{O}_{3}$ and $\mathrm{NiCO}_{3}$. The final residue shows a Curie temperature of 864 $\mathrm{K}$ in good agreement with the reported value [1] of $\mathrm{NiFe}_{2} \mathrm{O}_{4}$. The formation of the ferrite has also been confirmed by XRD powder pattern of the end product (Fig.3).

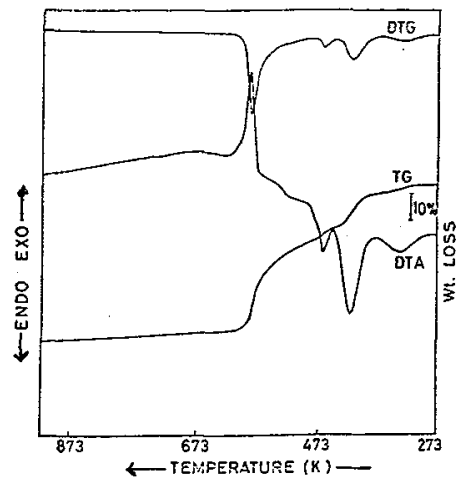

Fig. 1. STA curves of the complex at a heating rate of $10 \mathrm{~K} \mathrm{~min}^{-1}$.

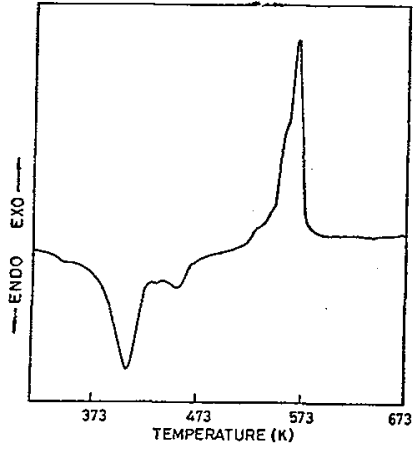

Fig. 2. DSC curve of the complex at a heating rate of $10 \mathrm{~K} \mathrm{~min}^{-1}$.

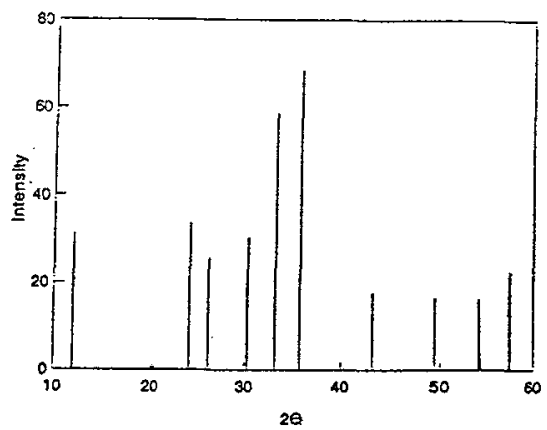

Fig. 3 XRD powder pattern of the end product.

The ferrite $\left(\mathrm{NiFe}_{2} \mathrm{O}_{4}\right)$ has been obtained at a temperature $(873 \mathrm{~K})$ much lower than that from ceramic method [10-11]. The saturation magnetization ( $4 \pi \mathrm{Ms}$ ) value of 4440 gauss of the ferrite shows its potential to function at high frequencies [10].

\section{References}

[1] Viswanathan B., Murthy V.RK.,Ferrite Materials ( Springer-Verlag, Berlin,1990).

[2] Srivastva A, Singh P, Gunjikar V.G., Sinha A.P.B.,Thermochimica Acta 86 (1985) 77.

[3] Randhawa B.S. Sandeep Kaur, Bassi P.S., Indian J Chem., 28A (1989)463.

[4] Bassi P.S. Randhawa B.S., Sandeep kaur, (Proc. 5 th ICF, 1989) pp 67.

[5] Bassi P.S. Randhawa B.S., Sandeep kaur, Indian J Chem, 31A (1992) 596.

[6] Ferraro J.R, Driver R., Walker W.R. , Wozniak W., Inorg Chem , 6(1967) 1586.

[7] Nakmoto K., Infrared Spectra of inorganic and coordination compunds, 2nd edition, John Wiley Interscience,

New York 1970

[8] Brar A.S., Randhawa B.S., J De Physiqye 44(1983) 1345.

[9] Randhawa B.S., Bassi P.S., Radiochem. Radioanal. Letts., 59(1983) 171.

[10] Encyclopedia of chemical Technology, 3rd edition, John Wiley and Sons, New York, 9(1978) 881.

[11] David I, Welch A.J.E., Trans Faraday Soc., 52(1956) 1642 